\title{
Who is Prescribing Psychotropic Medications in a Public Developmental-Behavioural Clinical Service and How Often?
}

Original Article

\author{
Authors: \\ Dr Katherine L Hughes ${ }^{1}$ \\ A/Prof Gehan Roberts ${ }^{1,2,3}$ \\ Research conducted at: \\ Royal Children's Hospital \\ 50 Flemington $\mathrm{Rd}$ \\ Parkville 3052 \\ Victoria
}

\section{Affiliations: \\ 1 Centre for Community Child Health, Royal Children's Hospital \\ 2 Population Health, Murdoch Children's Research Institute \\ 3 Department of Paediatrics, University of Melbourne}

\section{Correspondence to:}

Kate Hughes

0407508340

drkatehughes@gmail.com

Department of General Medicine

Royal Children's Hospital

50 Flemington $\mathrm{Rd}$

Parkville 3052

Victoria

\section{Acknowledgements}

We thank Dr Chris Ward and A/Prof Daryl Efron for their feedback on this paper. We also thank Dr Ahuva Segal for her assistance extracting the data from Epic EMR and Dr Jon Quach for his assistance with STATA analysis. There are no conflicts to declare.

This is the author manuscript accepted for publication and has undergone full peer review but has not been through the copyediting, typesetting, pagination and proofreading process, which may lead to differences between this version and the Version of Record. Please cite this article as doi: 10.1111/jpc.14676

This article is protected by copyright. All rights reserved. 
Figure 1: Breakdown of encounters and medication orders February 2017 to February 2018
Appointments
5069 encounters
2205 patients
Advanced Trainee 1620 (32\%)
Consultant 3359 (66.2\%)
Allied Health/other $90(1.8 \%)$

Any medication orders

1278 encounters (25.2\%)

1537 orders, 784 patients

Psychotropic orders

847 encounters ( $16.7 \%)$

981 orders, 501 patients

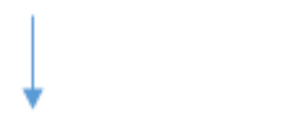

Psychotropic orders by group

Stimulants $611(62.3 \%)$

SSRIs $133(13.6 \%)$

SGA $110(11.2 \%)$

Clonidine 81 (8.3\%)

Atomoxetine 25 (2.5\%)

Other 21 (2.1\%)

Total 981
Advanced Trainee 222 (17.4\%)

Consultant 1056 (82.6\%)

Advanced Trainee total 72 (8.5\%)

Alone 47

Consultant-supported

stimulant 25

Consultant 775 (91.5\%)

This article is protected by copyright. All rights reserved. 
Figure 2: Number of psychotropic medications prescribed during single encounter

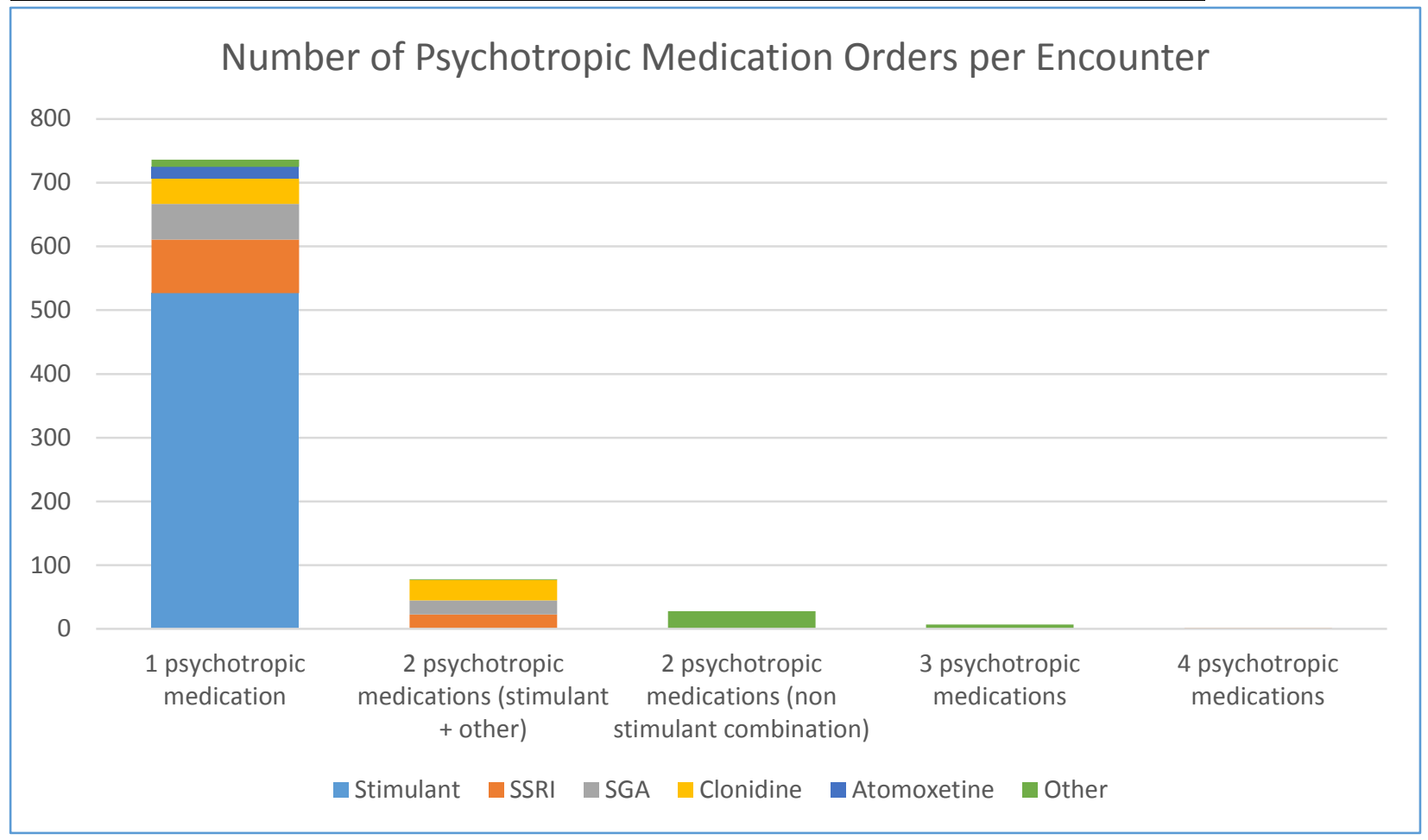

This article is protected by copyright. All rights reserved. 
Table 1: Comparison of characteristics between all encounters, by provider type and encounters where psychotropic medications were prescribed

\begin{tabular}{|lrrrr|}
\hline Characteristic & All encounters & \multicolumn{1}{l}{$\begin{array}{l}\text { Fellow } \\
\text { encounters }\end{array}$} & $\begin{array}{l}\text { Consultant } \\
\text { encounters }\end{array}$ & \multicolumn{1}{l|}{$\begin{array}{l}\text { Prescribed } \\
\text { psychotropics }\end{array}$} \\
\hline Age, mean (SD) & $8.04(3.99)$ & $6.87(3.69)$ & $8.68(4.01)$ & $10.99(3.10)$ \\
\hline Male & $72.9 \%$ & $73.5 \%$ & $72.5 \%$ & $81.4 \%$ \\
\hline "New" appointment & $22.9 \%$ & $39.3 \%$ & $14.5 \%$ & $4.6 \%$ \\
\hline
\end{tabular}

This article is protected by copyright. All rights reserved. 


\section{What is already known on this topic}

1) Patients with developmental-behavioural and mental health problems are commonly seen by paediatricians

2) Psychotropic prescribing rates are increasing, and the decision to prescribe psychotropic medications is complex

3) There is variation in care provided to patients, including in psychotropic prescribing practices of consultants

\section{What this paper adds}

1) Unexpectedly, patients seen in a public specialised developmental-behaviour paediatric service had lower rates of psychotropic medication prescribed compared with community paediatric patient populations

2) Advanced trainees are not prescribing psychotropic medication as often as consultants

3) Even within a small group of experienced paediatric consultants there is considerable variation in their rates of psychotropic prescribing

\section{Abstract}

Aim: Psychotropic prescribing by paediatricians is increasingly common, and there is considerable variation in care provided. The aims of this study were to examine current rates of psychotropic prescribing in the developmental-behavioural outpatient clinics at the Royal Children's Hospital's Centre for Community Child Health, and to compare rates between paediatric consultants and advanced trainees.

Methods: Data were extracted for appointment encounters from electronic medical records across 12 months in 2017. Patient demographics, provider and medication order data were analysed using Excel and STATA to calculate logistic regression, standard deviation, percentages and means.

Results: From 5069 encounters there were 847 (16.7\%) that included psychotropic prescribing. Advanced trainees prescribed psychotropic medications in only $4.4 \%$ of their encounters compared with consultants who prescribed these medications in $23 \%$ of encounters $(p<0.001)$. Stimulants were the most commonly prescribed psychotropic medication (62\%), either alone $(86.3 \%)$ or in combination $(13.7 \%)$.

Conclusions: Psychotropic prescribing rates were lower than expected. Advanced trainees may need more experience in psychotropic prescribing. 


\section{$\underline{\text { Key Words }}$}

Paediatricians; psychotropic drugs; practice patterns, physicians; clinical competence

This article is protected by copyright. All rights reserved. 


\section{Who is Prescribing Psychotropic Medications in a Public Developmental-Behavioural Clinical Service and How Often?}

\section{Background}

Developmental-behavioural and mental health $(\mathrm{DB} / \mathrm{MH})$ problems are prevalent amongst Australian children. Although rates vary geographically, international and local studies have shown that rates of psychotropic medication prescribing to children with $\mathrm{DB} / \mathrm{MH}$ problems are increasing ${ }^{1-4}$. Longitudinal Study of Australian Children (LSAC) data from 2012 to 2015 showed psychotropic medications were the second most commonly dispensed medication group comprising $18.7 \%$ of all prescriptions dispensed for $8-16 y 0^{5}$. Audits from 2008 and 2013 of Australian general paediatricians conducted by the Australian Paediatric Research Network (APRN) have shown that $\mathrm{DB} / \mathrm{MH}$ problems comprised more than $50 \%$ of new and review patient consultations ${ }^{6}$. The 2013 audit also found that one or more psychotropic medications were prescribed in $49.8 \%$ of all $\mathrm{DB} / \mathrm{MH}$ consultations. This shows the importance of general paediatricians having high level expertise in prescribing these medications.

Across inpatient, outpatient and emergency settings there is clear variation in paediatric care $^{7,8}$ and in psychotropic medication prescribing 9,10 . Reasons for this may include individual patient factors (such as age, co-morbidities, and access to insurance) and provider factors ${ }^{11-14}$. A 2008 UK study concluded that although the majority of paediatricians felt knowledgeable about the licensed usage and side effect profiles of psychotropic medications, few felt sufficiently competent in prescribing these medications ${ }^{15}$. During advanced general paediatric training in Australia and New Zealand psychotropic prescribing is currently a learning objective, but not directly assessed ${ }^{16}$. Anecdotally this has been identified as a major gap in training.

There are limited current Australian data on the rates of psychotropic prescribing across public $\mathrm{DB} / \mathrm{MH}$ services, and no information on advanced trainees' prescribing habits.
Aims
Our primary aim was to describe current rates of psychotropic prescribing within a specialist developmental-behavioural outpatient service (the Centre for Community Child Health Specialist Clinics) located within a large dedicated Children's Hospital (the Royal Children's Hospital, Melbourne). Secondary aims were to examine differences in psychotropic prescribing rates between consultants and advanced trainees and to examine variation in practice between consultants. We hypothesised that overall rates of psychotropic prescribing would be similar to the rates in the APRN audits. We also hypothesised that 
advanced trainees would prescribe psychotropic medications at a lower rate than consultants, and that rates of prescribing would vary between consultants.

\section{Methods}

The Centre for Community Child Health $(\mathrm{CCCH})$ at the Royal Children's Hospital $(\mathrm{RCH})$ in Melbourne, is the largest single provider of public developmental and behavioural outpatient services in Victoria. In contrast to other states, there is no overarching system of publicly funded community paediatricians working in local health areas in Victoria. The $\mathrm{CCCH}$ clinics are serviced by consultant paediatricians and supervised paediatric advanced trainees ( 5.2 full time equivalent) with limited allied health support ( 0.35 full time equivalent). Referrals are mostly from general practitioners, with the remainder from paediatricians and community allied health professionals. Geographically referrals are from all over Victoria, with approximately 2/3 coming from the North and West metropolitan and outer metropolitan areas. Referrals are triaged by advanced trainees and either accepted or redirected to other more local or appropriate services. Appointments are then made by reception staff without further triage relating to the perceived complexity of patient versus provider experience.

Data were extracted from the RCH electronic medical record (EMR) by designing a search report with the relevant encounters and their associated data. This was then converted into Excel format. All on-site outpatient encounters in the CCCH between February 62017 and February 42018 were included. These dates reflect the start and end dates for advanced trainees completing a 12-month fellowship in Community Child Health. There are seven different clinics within the department: Learning Difficulties, Behaviour, Development and Behaviour, Communication, Encopresis, Sleep and Unsettled Babies ${ }^{17}$. Exclusion criteria were medication orders made outside appointment encounters (such as telephone requests) and off-site appointments. Relevant demographic and clinical data recorded in the EMR were also collected, such as the patient's age, sex, date of visit, clinic visited, type of appointment (new/review), provider, problem list, reason for attendance, encounter diagnosis and medication orders. Sample characteristics were described using proportions and means. Diagnoses were analysed by merging problem list, encounter diagnosis and reason for attendance to capture all available information.

Providers were categorised as advanced trainees or consultants. Manual chart review was used to identify advanced trainee consultant-assisted stimulant prescriptions, where visit documentation was completed by both an advanced trainee and a consultant. These were then analysed as advanced trainee prescriptions.

Medication orders were initially grouped into stimulants, selective serotonin reuptake inhibitors (SSRIs), second-generation antipsychotics (SGA), Clonidine, Atomoxetine and 
"other". Within "other" there were 51 different medications, of which 8 were retrospectively classified as psychotropic and included in analyses. These were benzodiazepines, anti-convulsants and Venlafaxine.

Microsoft Excel and STATA were used for statistical analysis to calculate logistic regression, percentages, means and standard deviations.

\section{Ethics}

Ethics approval was obtained prospectively from the Royal Children's Hospital Human Research Ethics Committee, HREC number LNR/18/RCHM/264.

\section{Results}

Across a twelve month period between February 2017 and February 2018 there were 5069 patient encounters in the Centre for Community Child Health outpatient clinics, involving 27 providers (Figure 1). This represented 2205 individual patients. Overall $16.7 \%$ of encounters involved psychotropic prescribing.

1163 (23\%) of these encounters were new patient consultations (Table 1). Of the 847 encounters with a psychotropic medication prescription $82.5 \%$ had a diagnosis listed of ADHD, $30.7 \%$ of ASD and $24.7 \%$ of a mood disorder (total more than $100 \%$ due to encounters with multiple diagnoses). Patients prescribed psychotropic medications were more likely to be male ( $81.4 \%$ ) and older (mean 11 years, SD 3.10) compared with the sex and age distributions in the overall encounters.

Stimulant medication was the most commonly prescribed, usually as a single agent (527 out of $611,86.3 \%$ ). $86.9 \%$ of encounters prescribed a psychotropic medication were prescribed only one psychotropic agent, $15 \%$ were prescribed two agents $<1 \%$ each were prescribed three or four agents (Figure 2). The most common combinations were clonidine plus stimulant (32), SSRI plus stimulant (23) and SGA plus stimulant (22).

Advanced trainees undertook $32 \%$ of all encounters, however prescribed only $8.5 \%$ of all psychotropic medication orders (Figure 1). Advanced trainees were less likely to prescribe psychotropic medication (4.4\% of their encounters, including consultant-assisted stimulants) compared with consultants ( $23.1 \%$ of their encounters), an Odds ratio (OR) $0.09(95 \% \mathrm{Cl}$ 0.07 to 0.13 ), $p<0.001$. Advanced trainees saw younger patients and more "new" patients compared with consultants (Table 1). Logistic regression was performed to examine whether the age of patients or "new" patient status (versus review) were confounders in this difference between advanced trainees and consultants. The decreased odds of advanced trainees prescribing persisted, with an adjusted OR 0.16 (95\% $\mathrm{Cl} 0.11-0.21)$, $p<0.001$. When further analysed by encounters in the specialist development and behaviour 
clinics only (excluding five other CCCH clinics encompassing $35 \%$ of total encounters) psychotropic prescribing rate was $39.6 \%$ for consultants and $7.9 \%$ for advanced trainees.

There was a high degree of variability by consultant in prescribing rates of psychotropic medication, even if using data solely from the sub-set of consultants working in the specialist development and behaviour clinics, ranging from $11.8 \%$ to $63.1 \%$ of their encounters.

\section{Discussion}

We found that less than $20 \%$ of all CCCH encounters were prescribed psychotropic medication, and most of those were single agent therapy. The rate of psychotropic prescribing across all encounters within the $\mathrm{CCCH}$ was low compared to the APRN audit findings, where the psychotropic prescribing rate was $49.8 \%$. This disproved our first hypothesis. The possible reasons for this are myriad. Firstly, it is possible that within these clinics there is a particular focus on holistic developmental assessment, as well as optimising behavioural and psychoeducational interventions before medications when compared with practices outside the hospital setting.

A clear factor associated with the lower total psychotropic prescribing rate is that less than $5 \%$ of all advanced trainee encounters involved psychotropic prescribing, while they were responsible for a third of total encounters. Trainees spend six months in most clinics, seeing new referrals rather than previous trainees' reviews. It is possible that the above mentioned focus of initially trialling non-medication management options means that the decision to prescribe was not made in this time frame. Perhaps if trainees were seeing patients with prior assessment or treatment, rates may have been higher. However, our logistic regression analysis showed the difference persisted even once this was adjusted for.

The stark difference in prescribing rates between this study and the APRN audits, as well as the consultant versus trainee comparison raises the question: how do doctors decide when to prescribe? An interview-based study done in Australia in 2014 to evaluate paediatricians' decision making about stimulant prescribing showed it to be a complex process ${ }^{18}$. They found that there are clinical, child/family and paediatrician factors, all of which are weighed up before a decision is made. In the paediatrician factors, previous experience and success with the medication were important. In a trainee context, a larger survey of US psychiatry trainees in 2010 about pharmacological treatments for bipolar disorder found that confidence level in mood stabiliser initiation was significantly associated with the number of times that medication had been prescribed in the previous year ${ }^{19}$. It postulated that prescribing patterns and skills are developed during residency training. In Australia and New Zealand paediatric trainees are required to complete a six-month term in Developmental and Psychosocial Training to gain their Royal Australasian College of Physicians (RACP) 
fellowship. This term may be in mental health or DB paediatrics, but can also be in palliative care or rehabilitation. In effect, this means that general paediatric trainees may gain RACP fellowship with minimal practical experience in psychotropic prescribing. When considering the results of our study alongside the US psychiatry study, it appears that even trainees undertaking a 12 month $\mathrm{DB} / \mathrm{MH}$ rotation are not having much direct prescribing experience, which we propose is an important factor in developing the competence required for their likely casemix as consultant general paediatricians (as demonstrated by the APRN study ${ }^{6}$ ).

Australian articles from $1999^{20}$ and $2007^{21}$ with similar concerns about training indicate that this is a long-standing challenge, but with rising rates of prescribing, the need for achieving competency in prescribing during training is arguably becoming more critical. Further, it is not a situation unique to Australia. The American Academy of Pediatrics acknowledged that their trainees are entering the primary care workforce with limited collaborative and supervised experience in early childhood mental health ${ }^{22}$. The RACP is currently renewing initially basic, and then advanced, training curricula with a focus on competencies and 'Entrustable Professional Activities' (EPA) as well as knowledge ${ }^{23}$. A 2015 EPA pilot in the chapter for community child health included use of psychotropic medications ${ }^{24}$. The popularity of workshops such as the Neurodevelopmental and Behavioural Paediatric Society of Australasia 'Rational Prescribing' day ${ }^{25}$ indicates the need for more support in this area. We suggest that the experience from the EPA pilot should be fast-tracked into the general paediatric curriculum.

This study showed a high level of variation in rates of psychotropic medication prescribing between different consultants. High variation was also found in the APRN study ${ }^{6}$, as well as two American studies of psychotropic prescribing across different sites with ranges of 4.3$25.8 \%{ }^{9}$ and $4.0-49.3 \%{ }^{11}$ respectively. The reasons proposed for this variation in the US studies include access to behavioural and psychological supports as well as to psychiatrists. Both of these would also apply in the Australian context. We also propose that individual preference and previous experiences also play important roles. Another factor in this disparity is comfort with, and utilisation of, off-label prescribing, where paediatric psychotropic prescribing has out-paced evidence ${ }^{22}$. From a high of up to $80 \%$ of psychotropic prescribing in the early-2000s this has reduced to $25-50 \%^{26-28}$, likely due to an increase in the approved range of uses ${ }^{29}$. We further acknowledge that there is currently no "gold standard" of when (or not) to prescribe these medications in this population. Working towards minimising unwarranted variation in care is an important goal in providing a best practice model of care for $\mathrm{DB} / \mathrm{MH}$ patients ${ }^{7}$. Finally, this care variation should also be considered from a community perspective: what degree of variability is tolerable, and should there be transparency around this? 
This study has several limitations. The EMR data are at an encounter rather than patient level, and provide a "snapshot" of prescriptions for that encounter rather than a view of psychotropic prescribing over time. The information also shows medications ordered, not whether the prescription is filled, commenced or continued by families. It is unknown whether these lower overall rates of psychotropic prescribing and very low advanced trainee prescribing are also seen in other tertiary services across Australia.

\section{Conclusions}

This study shows that children attending specialist CCCH developmental-behavioural clinics at the Royal Children's Hospital, Melbourne, in 2017 were less likely to be prescribed psychotropic medications compared with community general paediatric settings in Australia. There was also substantial variation in psychotropic prescribing rates between consultants, and between trainees and consultants as provider groups. It raises the question as to whether advanced trainees would benefit from more practical experience prescribing, monitoring and managing patients on psychotropic medications as one factor in achieving the competency required for the current casemix of Australian general paediatric consultant outpatient practice. Further research on barriers and enablers to prescribing, as well as having psychotropic prescribing as a core competency in advanced training may improve this.

1. Abbas S, Ihle P, Adler JB, et al. Psychopharmacological Prescriptions in Children and Adolescents in Germany. Dtsch Arztebl Int. 2016;113(22-23):396-403.

2. Hollingworth SA, Nissen LM, Stathis SS, Siskind DJ, Varghese JM, Scott JG. Australian national trends in stimulant dispensing: 2002-2009. Aust N Z J Psychiatry. 2011;45(4):332-6.

3. Steinhausen $\mathrm{HC}$, Bisgaard C. Nationwide time trends in dispensed prescriptions of psychotropic medication for children and adolescents in Denmark. Acta Psychiatr Scand. 2014;129(3):221-31.

4. Karanges EA, Stephenson CP, McGregor IS. Longitudinal trends in the dispensing of psychotropic medications in Australia from 2009-2012: focus on children, adolescents and prescriber specialty. Aust N Z J Psychiatry. 2014;48(10):917-31.

5. Tew M, Daryl Efron D, Hiscock H, Dalziel K. What Medications are Australian Children Prescribed? Evidence from the Longitudinal Study of Australian Children2018. 335-6 p.

6. Hiscock H, Danchin MH, Efron D, et al. Trends in paediatric practice in Australia: 2008 and 2013 national audits from the Australian Paediatric Research Network. J Paediatr Child Health. 2017;53(1):55-61.

7. Jongeling B, Roberts G. Models of care in neurodevelopmental-behavioural paediatrics. J Paediatr Child Health. 2018;54(10):1100-3.

8. Hiscock H, Perera P, McLean K, et al. Variation in paediatric clinical practice: A review of care in inpatient, outpatient and emergency department settings. J Paediatr Child Health. 2016;52(7):691-3. 
9. Mayne SL, Ross ME, Song L, et al. Variations in Mental Health Diagnosis and Prescribing Across Pediatric Primary Care Practices. Pediatrics. 2016;137(5):e20152974.

10. House SA, Goodman DC, Weinstein SJ, Chang CH, Wasserman JR, Morden NE. Prescription Use among Children with Autism Spectrum Disorders in Northern New England: Intensity and Small Area Variation. The Journal of pediatrics. 2016;169:277-83 e2.

11. Jackel C, Shults J, Wiley S, Meinzen-Derr J, Augustyn M, Blum N. Factors Associated with Developmental Behavioral Pediatricians Prescribing Psychotropic Medication to Children with Autism Spectrum Disorder: A Study of Three DBPNet Sites. J Dev Behav Pediatr. 2017;38(8):584-92. 12. Tulisiak AK, Klein JA, Harris E, et al. Antidepressant Prescribing by Pediatricians: A MixedMethods Analysis. Curr Probl Pediatr Adolesc Health Care. 2017;47(1):15-24.

13. Mitchell PB, Levy F, Hadzi-Pavlovic D, et al. Practitioner characteristics and the treatment of children and adolescents with attention deficit hyperactivity disorder. J Paediatr Child Health. 2012;48(6):483-9.

14. Sheldrick RC, Leslie LK, Rodday AM, Parsons SK, Saunders TS, Wong JB. Variations in Physician Attitudes Regarding ADHD and Their Association With Prescribing Practices. J Atten Disord. 2015;19(7):569-77.

15. McNicholas F. Psychotropic prescribing practices of paediatricians in the UK. Child Care Health Dev. 2001;27(6):497-508.

16. Physician Readiness for Expert Practice (PREP) Training Program, General Paediatrics Advanced Training Curriculum. Royal Australasian College of Physicians; 2013.

17. RCH CCCH Clinics 2018 [cited 2018 December 11]. Available from: https://www.rch.org.au/ccch/services/specialist-clinics/.

18. Chow SJ, Sciberras E, Gillam LH, Green J, Efron D. Paediatricians' decision making about prescribing stimulant medications for children with attention-deficit/hyperactivity disorder. Child Care Health Dev. 2014;40(3):301-8.

19. Rakofsky JJ, Dunlop BW. US psychiatric residents' treatment of patients with bipolar disorder. J Clin Psychopharmacol. 2012;32(2):231-6.

20. Oberklaid F. An evidence-based approach to paediatric training and practice: More questions than answers. J Paediatr Child H. 1999;35(1):14-5.

21. Roongpraiwan R, Efron D, Sewell J, Mathai J. Comparison of mental health symptoms between children attending developmental/behavioural paediatric clinics and child and adolescent mental health service. J Paediatr Child Health. 2007;43(3):122-6.

22. Gleason MM, Goldson E, Yogman MW, et al. Addressing Early Childhood Emotional and Behavioral Problems. Pediatrics. 2016;138(6):e20163025.

23. RACP Basic Training Curricula Renewal 2018 [Available from:

https://www.racp.edu.au/innovation/education-renewal/basic-training-curricula/standards.

24. Briones N, O'Keeffe M. Advanced Training in Community Child Health Entrustable Professional Activities Pilot Evaluation Report December 2015. Royal Australasian College of Physicians; 2015.

25. NBPSA Event Page 2018 [Available from: https://nbpsa.org/events

26. Huskamp HA, Horvitz-Lennon M, Berndt ER, Normand ST, Donohue JM. Patterns of Antipsychotic Prescribing by Physicians to Young Children. Psychiatr Serv. 2016;67(12):1307-14.

27. Brauner JV, Johansen LM, Roesbjerg T, Pagsberg AK. Off-Label Prescription of Psychopharmacological Drugs in Child and Adolescent Psychiatry. J Clin Psychopharmacol. 2016;36(5):500-7. 
28. Kearns M, Hawley K. Predictors of Polypharmacy and Off-Label Prescribing of Psychotropic Medications2014. 438-47 p.

29. Off-Label Use of Drugs in Children. Pediatrics. 2014;133(3):563.

This article is protected by copyright. All rights reserved. 
Figure 1: Breakdown of encounters and medication orders February 2017 to February 2018
Appointments
5069 encounters
2205 patients
Advanced Trainee 1620 (32\%)
Consultant 3359 (66.2\%)
Allied Health/other $90(1.8 \%)$

Any medication orders

1278 encounters (25.2\%)

1537 orders, 784 patients

Psychotropic orders

847 encounters ( $16.7 \%)$

981 orders, 501 patients

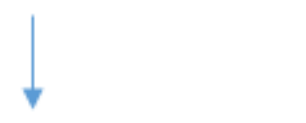

Psychotropic orders by group

Stimulants $611(62.3 \%)$

SSRIs $133(13.6 \%)$

SGA $110(11.2 \%)$

Clonidine 81 (8.3\%)

Atomoxetine 25 (2.5\%)

Other 21 (2.1\%)

Total 981
Advanced Trainee 222 (17.4\%)

Consultant 1056 (82.6\%)

Advanced Trainee total 72 (8.5\%)

Alone 47

Consultant-supported

stimulant 25

Consultant 775 (91.5\%)

This article is protected by copyright. All rights reserved. 
Figure 2: Number of psychotropic medications prescribed during single encounter

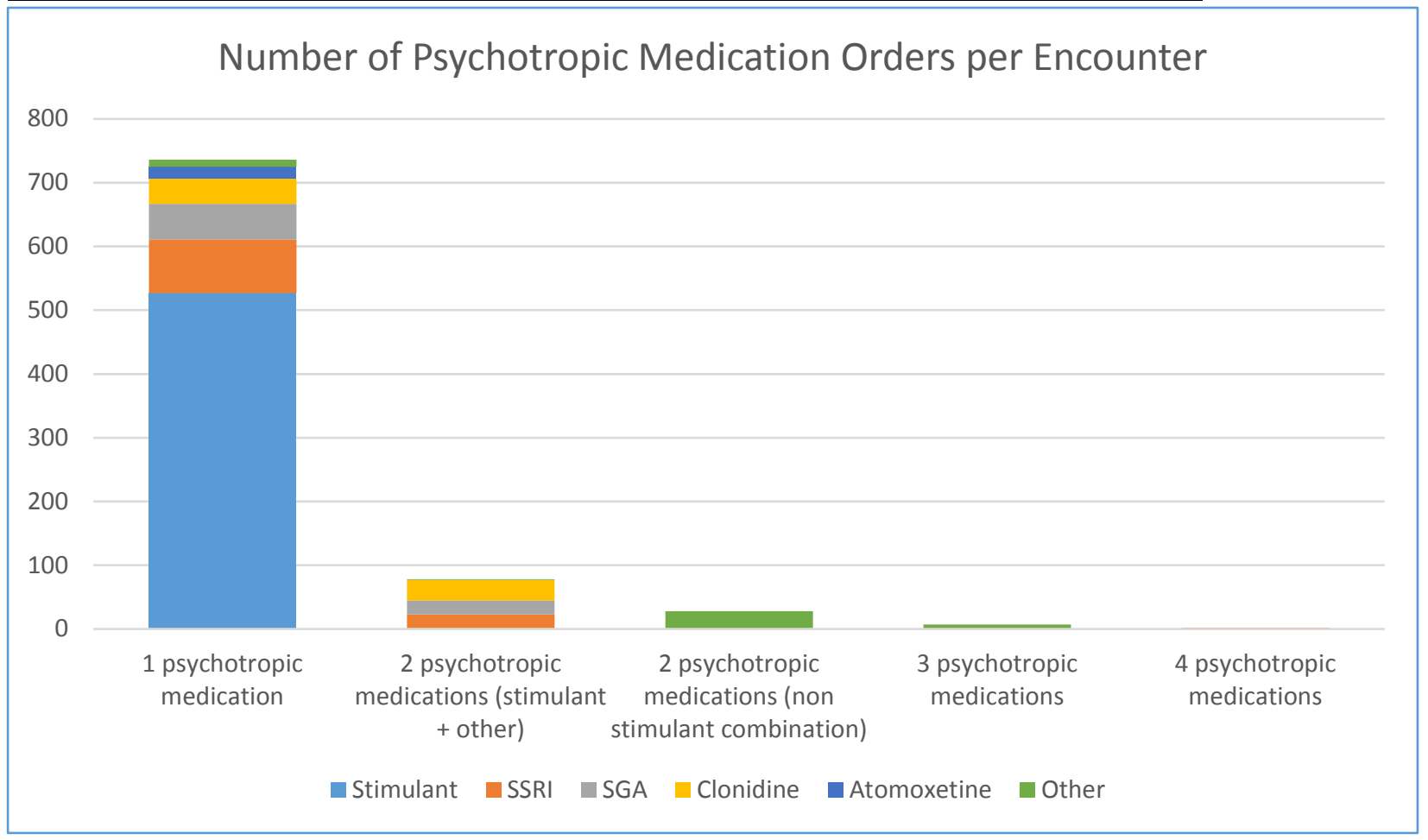

This article is protected by copyright. All rights reserved. 


\section{University Library}

\section{- M M N E R VA A gateway to Melbourne's research publications}

Minerva Access is the Institutional Repository of The University of Melbourne

Author/s:

Hughes, KL;Roberts, G

Title:

Who is prescribing psychotropic medications in a public developmental-behavioural clinical service and how often?

Date:

2019-11-13

Citation:

Hughes, K. L. \& Roberts, G. (2019). Who is prescribing psychotropic medications in a public developmental-behavioural clinical service and how often?. JOURNAL OF PAEDIATRICS AND CHILD HEALTH, 56 (4), pp.532-536. https://doi.org/10.1111/jpc.14676.

Persistent Link:

http://hdl.handle.net/11343/286613 